\title{
RADIO GRACEFUL HAMMING GRAPHS
}

\author{
AmANDA NiEDZialomski \\ University of Tennessee at Martin \\ e-mail: aniedzia@utm.edu
}

\begin{abstract}
For $k \in \mathbb{Z}_{+}$and $G$ a simple, connected graph, a $k$-radio labeling $f$ : $V(G) \rightarrow \mathbb{Z}_{+}$of $G$ requires all pairs of distinct vertices $u$ and $v$ to satisfy $|f(u)-f(v)| \geq k+1-d(u, v)$. We consider $k$-radio labelings of $G$ when $k=\operatorname{diam}(G)$. In this setting, $f$ is injective; if $f$ is also surjective onto $\{1,2, \ldots,|V(G)|\}$, then $f$ is a consecutive radio labeling. Graphs that can be labeled with such a labeling are called radio graceful. In this paper, we give two results on the existence of radio graceful Hamming graphs. The main result shows that the Cartesian product of $t$ copies of a complete graph is radio graceful for certain $t$. Graphs of this form provide infinitely many examples of radio graceful graphs of arbitrary diameter. We also show that these graphs are not radio graceful for large $t$.
\end{abstract}

Keywords: radio labeling, radio graceful graph, Hamming graph.

2010 Mathematics Subject Classification: 05C78.

\section{REFERENCES}

[1] K.F. Benson, M. Porter and M. Tomova, The radio numbers of all graphs of order $n$ and diameter $n-2$, Matematiche (Catania) 68 (2013) 167-190.

[2] G. Chartrand, D. Erwin, P. Zhang and F. Harary, Radio labelings of graphs, Bull. Inst. Combin. Appl. 33 (2001) 77-85.

[3] G. Chartrand and P. Zhang, Radio colorings of graphs-a survey, Int. J. Comput. Appl. Math. 2 (2007) 237-252.

[4] C. Fernandez, A. Flores, M. Tomova and C. Wyles, The radio number of gear graphs, arXiv:0809.2623.

[5] J. Fiala, J. Kratochvíl and A. Proskurowski, Distance constrained labeling of precolored trees, Theoretical Computer Science, Torino, 2001, Lecture Notes in Comput. Sci. (Springer, Berlin, 2001) 285-292.

doi:10.1007/3-540-45446-2_18 
[6] P.C. Fishburn and F.S. Roberts, No-hole L(2,1)-colorings, Discrete Appl. Math. 130 (2003) 513-519. doi:10.1016/S0166-218X(03)00329-9

[7] P.C. Fishburn and F.S. Roberts, Full color theorems for L $(2,1)$-colorings, SIAM J. Discrete Math. 20 (2006) 428-443. doi: $10.1137 / \mathrm{S} 0895480100378562$

[8] J.R. Griggs and R.K. Yeh, Labelling graphs with a condition at distance 2, SIAM J. Discrete Math. 5 (1992) 586-595. doi:10.1137/0405048

[9] W.K. Hale, Frequency assignment: theory and applications, in: Proceedings of the IEEE 68 (1980) 1497-1514. doi:10.1109/PROC.1980.11899

[10] X. Li, V. Mak and S. Zhou, Optimal radio labellings of complete m-ary trees, Discrete Appl. Math. 158 (2010) 507-515. doi:10.1016/j.dam.2009.11.014

[11] D. D.-F. Liu, Radio number for trees, Discrete Math. 308 (2008) 1153-1164. doi:10.1016/j.disc.2007.03.066

[12] D.D.-F. Liu and M. Xie, Radio number for square of cycles, in: Proceedings of the Thirty-Fifth Southeastern International Conference on Combinatorics, Graph Theory and Computing, Congr. Numer. 169 (2004) 101-125.

[13] D.D.-F. Liu and X. Zhu, Multilevel distance labelings for paths and cycles, SIAM J. Discrete Math. 19 (2005) 610-621. doi:10.1137/S0895480102417768

[14] P. Martinez, J. Ortiz, M. Tomova and C. Wyels, Radio numbers for generalized prism graphs, Discuss. Math. Graph Theory 31 (2011) 45-62. doi:10.7151/dmgt.1529

[15] M. Morris-Rivera, M. Tomova, C. Wyels and A. Yeager, The radio number of $C_{n} \square C_{n}$, Ars Combin. 120 (2015) 7-21.

[16] L. Saha and P. Panigrahi, Antipodal number of some powers of cycles, Discrete Math. 312 (2012) 1550-1557. doi:10.1016/j.disc.2011.10.032

[17] L. Saha and P. Panigrahi, On the radio number of toroidal grids, Australas. J. Combin. 55 (2013) 273-288.

[18] L. Saha and P. Panigrahi, A lower bound for radio $k$-chromatic number, Discrete Appl. Math. 192 (2015) 87-100. doi:10.1016/j.dam.2014.05.004

[19] B. Sooryanarayana and P. Raghunath, Radio labeling of cube of a cycle, Far East J. Appl. Math. 29 (2007) 113-147.

[20] R. Sweetly and J.P. Joseph, The radio number of $\left(W_{n}: 2\right)$ graphs, J. Discrete Math. Sci. Cryptogr. 12 (2009) 729-736. doi:10.1080/09720529.2009.10698268 
[21] R.K. Yeh, A survey on labeling graphs with a condition at distance two, Discrete Math. 306 (2006) 1217-1231.

doi:10.1016/j.disc.2005.11.029

Received 31 July 2015

Revised 16 January 2016

Accepted 16 January 2016 